\title{
EDITORIAL
}

\section{HOW DOES A REVIEWER MAKE A DIFFERENCE?}

The reviewer of a peer-reviewed archival journal article makes a key difference between such a publication and a typical conference proceedings article. Without dedicated and competent reviewers, the quality of the journal suffers. However, reviewing is voluntary, performed as a service to the technical community. Unlike an editor, the reviewer has to remain anonymous so that he or she can freely give objective comments. As a result, there is no name recognition. Neither does the reviewer get any form of compensation for his or her work. The reasons that reviewers spend time and effort to do a good review are that they have a passion for their fields of expertise, and also they wish to get a constructive review of their own paper some day. "Do for others as you would have done to you."

In $J^{3}$, since I take a last look at each article before the acceptance notice is approved and sent to the author, I have the opportunity to appreciate the good work of many reviewers and am aware of the sloppy work of some others. Because review work is so vital to a journal, I would like to make a list of the traits of a good reviewer and put it to print.

I. A good reviewer responds to a request promptly. If he declines, the reasons should be given. If the reason is that the topic is out of his area of expertise, he can identify his own fields of expertise for future reviews. If he is simply too busy to handle the manuscript at hand, he can indicate his continued interest in the field and the next available time to review future articles.

2. A good reviewer does not procrastinate once he accepts the request. Procrastination does not reduce the time needed for review. However, it does make you feel guilty and is habit forming.

3. A good reviewer reviews the article constructively. I have seen many objective constructive reviews for which the authors sincerely thank the reviewers for making suggestions to improve the article.

4. A good reviewer reviews the article carefully. He looks at the major findings, the validity of the theory, and the soundness of the experiment. He checks the figures and puts himself in the shoes of a reader who needs information from the article. He makes sure that there is no key information missing. He checks the diligence of the authors references to relevant works.

5. Sometimes the authors may be too wordy. They may be too repetitive. There may be too much irrelevant data. The information flow may be illogical. A good reviewer would point out these errors and ask the authors for more efficient writing.

6. A good reviewer rejects articles with good reasons. The subject matter may not fit the journal. The major findings may be wrong. There may be insignificant contribution to the technical knowledge base. There may be commercialism. He rejects the article objectively and sensibly.

7. Some reviewers rate the manuscript excellent and accept it without substantiating their opinion. When I see this kind of review, I simply consider the review invalid and will proceed to find another reviewer who substantiates his opinion.

8. A good article usually has a sufficient number of references and a reasonable percentage of self references. As an expert in the field, the reviewer should not hesitate to point out missing references. Especially, any relevant references from $J M^{3}$ should be recommended.

I am sure this is not an exhaustive list, and it does not include ways to compensate a reviewer for good efforts. Please send me your opinion on what you expect of a reviewer and what you do as a reviewer. In the latter case, tell me what you consider a proper gesture of appreciation for your honorable job as a $J M^{3}$ reviewer. In other words, review this editorial and give me your feedback on improving the review process. You may send me an e-mail at burnlin@tsmc.com.

Happy reviewing! Happy reading! Happy authoring!

\section{Burn J. Lin \\ Editor-in-Chief}

